Journal of Applied Sciences and Nanotechnology

Journal homepage: https://jasn.uotechnology.edu.iq/

\title{
Preparation and Characterization of Electron Transfer Layer for Perovskite Solar Cells
}

\author{
Adam K. Kadhim*, Atheer I. Abd Ali, Mohammad R. Mohammad \\ Department of Applied Sciences, University of Technology, Iraq
}

\section{Article information}

Article history:

Received: May, 07, 2021

Accepted: June, 20, 2021

Available online: September, 18, 2021

Keywords:

Perovskite,

Graphene,

Triple cation

*Corresponding Author:

Adam K. Kadhim

as.18.70@grad.uotechnology.edu.iq

\begin{abstract}
In this paper, we present triple cation perovskites because it has excellent stability and PV performance. To characterize the triple-cation perovskite solar cells, X-ray diffraction, Field emission scanning electron microscope, and Ultraviolet-visible spectroscopy were used. The performance of perovskite solar cells was improved by reducing graphene oxide/bismuth oxide mixed mesoporous titanium dioxide as an effective electron transport layer. The perovskite layer deposited onto modified $\mathrm{TiO}_{2}$ layer showed a larger grain size with better crystalline nature. The optimum device has fabricated at room temperature without a glove box and obtained a power conversion efficacy of $17 \%$.
\end{abstract}

DOI: 10.53293/jasn.2021.3521.1025, Department of Applied Science, University of Technology

This is an open access article under the CC BY 4.0 License

\section{Introduction}

Global energy exhaustion has increased due to population growth and manufacturing development, predestine renewable energy sources for long-term sustainability [1-6]. Nevertheless, renewable energy generation remains a balancing rule between cost, efficiency, and environmental impact [7-10]. However, harvesting energy directly from sunlight using photovoltaic (PV) devices holds promise for product energy globally and on a microscopic scale [11, 12]. PSCs (perovskite solar cells) are a novel kind of solar cell that has a cubic structure. It has the typical chemical formula $\mathrm{ABX} 3$, with the A sign indicating an organic cation; the most frequent ones are methylammonium (MA), formamidinium (FA), and cesium (CS)[13]. The term B is a sign for inorganic (metallic) elements such as lead $(\mathrm{Pb})$ and tin $(\mathrm{Sn})$, while $\mathrm{X}$ refers to halide-based material chloride $(\mathrm{Cl})$, bromide $(\mathrm{Br})$, and iodide (I). Perovskite has excellent properties, like adjustable bandgap, higher optical absorption coefficient, the length of charge diffusion is longer, and higher charge carrier mobility [14]. PSCs promise to produce a solar cell's third generation because the power conversion efficiency (PCE) increased from 3.8\% to 25.2\% from 2009 until now $[15,16]$.

There are three kinds of perovskite cations: single cation methylammonium lead halide $\mathrm{CH}_{3} \mathrm{NH}_{3} \mathrm{PbI}_{3}$, which is inefficient and has poor thermal and air stability.[17, 18]. The second is the double cation formamidiniummethylammonium lead halide $\mathrm{CH}\left(\mathrm{NH}_{2}\right)_{2}, \mathrm{CH}_{3} \mathrm{NH}_{3} \mathrm{PbI}_{3}\left(\mathrm{MAFAPb}_{3}\right)$, which has a higher PCE than $\mathrm{MAPbI}_{3}$ but poorer stability when compared with $\mathrm{MAPbI}_{3}$. The last one is triple cation $\mathrm{CsFAMAPbI}$ perovskite, which uses Cs to enhance MA/FA perovskite molecules further. These materials have a high PCE and excellent thermal stability.[19, 20].Particulate materials with at least one dimension of fewer than 100 nanometers are known as nanoparticles. Nanomaterials have the ability to tamper with light and regulate energy flow at atomic scales [21]. Nanostructured solar cells, also known as nanowire, mesoscopic, and quantum dot solar cells, are third- or next- 
generation solar cells based on nanostructures or nanostructured interfaces [22, 23]. They present many innovative ways to convert solar energy into electricity or heat (in PV devices). Graphene is a carbon material with a hexagonal structure like a honeycomb lattice with $0.34 \mathrm{~nm}$ thickness [24]. Due to its amazing characteristics, such as high thermal and chemical durability, high electrical conductivity, high charge mobility, and low-cost manufacturing, graphene and graphene-based hybrid nanostructures have been utilized in PSCs [25]. Reduce graphene oxide (rGO) has excellent chemical, mechanical stability, high thermal conductivity, suitable optical properties, and easily varied chemical functionalization [26]. Because of its remarkable properties, it can be a promising dopant for the electron transport layer (ETL) to enhance the efficiency of PSCs [27]. Bismuth (Bi) is also a benign element, and its ionic radii comply with the tolerance factor rule, improving the stability of Bi-based perovskite materials[17, 28]. Furthermore, Bi-based perovskite materials were discovered to have a greater absorption coefficient, making them an effective light-absorbing material for solar cell applications. Therefore, the performance of Bi-based perovskite structures has been encouraging and efficient charge extraction layers $[29,30]$. Bismuth oxide $\left(\mathrm{Bi}_{2} \mathrm{O}_{3}\right)$ has been good electrochemical properties, stabilities, and relatively high power. Bi-based materials provide acceptable features for PVs, such as high absorption coefficients and appropriate bandgaps, as well as other appealing traits such as robustness and stability [31]. Most importantly, $\mathrm{Bi}_{2} \mathrm{O}_{3}$ prevents halide perovskites' corrosion and is a substantial stable metal for halide perovskites even under the most challenging circumstances [32].

\section{Theoretical Part}

A solar cell is an electrical device that receives solar energy and transforms it directly into electricity. When sunlight strikes a solar cell, it generates both current and voltage. As a result, solar energy may be used to create electricity. This technique necessitates the use of a substance that can absorb sunlight and produce electron-hole pairs. Before being gathered by the contact layers, these electron-hole pairs might spread and drift. These highenergy electrons and holes can create a photo-current when they flow via an external circuit from a solar cell. Finally, the higher-energy electrons and holes expend their energy into an external load before returning to the solar cell to recombine. Although various materials are viable for photovoltaic energy conversion, we most commonly employ PN junctions to convert solar energy to electricity in reality.

\section{Experimental Procedure \\ Materials Synthesis}

A novel nanocomposite of $\mathrm{rGO} / \mathrm{Bi}_{2} \mathrm{O}_{3}$ was synthesized via dispersing $\mathrm{rGO}(98.5 \%$ and conductivity $\sim 600 \mathrm{~S} / \mathrm{m}$, Merck) and $\mathrm{Bi}_{2} \mathrm{O}_{3}(98.5 \%, 25-35 \mathrm{~nm}$, Merck) separately in ethanol and stirring at room temperature. Later, $2 \%$ of $\mathrm{Bi}_{2} \mathrm{O}_{3}$ solution was added to $\mathrm{rGO}$ dispersion and mixed overnight at $70{ }^{\circ} \mathrm{C}$. After that, $\mathrm{rGO} / \mathrm{Bi}_{2} \mathrm{O}_{3}$ mixture was gathered via centrifugation and rinsed with deionized water four times. Finally, the resultant mixture was heated at $80{ }^{\circ} \mathrm{C}$ with a furnace overnight.

\section{PSCs Fabrication}

To pattern the FTO substrates, it was cleaned with distilled water, acetone, and IPA (99.8\%, Sigma-Aldrich) in a sonication bath for $15 \mathrm{~min}$. After that, the FTO glasses were heated at $50{ }^{\circ} \mathrm{C}$ for $10 \mathrm{~min}$. The compact $\mathrm{TiO}_{2}(\mathrm{c}-$ $\mathrm{TiO}_{2}$ ) films were then prepared by depositing an acid mixture of titanium isopropoxide (purity of 98\%, EXIR) at $3000 \mathrm{rpm}$ for $40 \mathrm{~s}$. Eventually, the pure $\mathrm{mp}-\mathrm{TiO}_{2}$ or $\mathrm{rGO} / \mathrm{Bi}_{2} \mathrm{O}_{3}$ modified $\mathrm{mp}-\mathrm{TiO}_{2}$ films were spinning-coated over c- $\mathrm{TiO}_{2}$ with a speed of $3000 \mathrm{rpm}$ for $40 \mathrm{~s}$. Next, to prepare modified mp- $\mathrm{TiO}_{2}$ precursors, $2 \%$ content of the $\mathrm{rGO} / \mathrm{Bi}_{2} \mathrm{O}_{3}$ solution in chlorobenzene was inserted into the dispersed $\mathrm{TiO}_{2}$ and mixed for $120 \mathrm{~min}$. Next, both c$\mathrm{TiO}_{2}$ and $\mathrm{mp}-\mathrm{TiO}_{2}$ films were annealed at $500{ }^{\circ} \mathrm{C}$ for $60 \mathrm{~min}$. Next, the perovskite layer was prepared by stirring a mixture of $\mathrm{PbI}_{2}(600 \mathrm{mg})$ and lead bromide $(15 \mathrm{mg})$ in DMF $(950 \mu \mathrm{l})$ amount $10 \%$ of $\mathrm{CsPbI}_{3}$ and then was deposited on $\mathrm{FTO} / \mathrm{c}-\mathrm{TiO}_{2} / \mathrm{mp}-\mathrm{TiO}_{2}$ substrates by spin-coating at $2000 \mathrm{rpm}$ for $40 \mathrm{~s}$, followed by annealing at 70 ${ }^{\circ} \mathrm{C}$ for $2 \mathrm{~min}$. Next, a solution of formamidinium iodide, methylammonium bromide, and methylammonium chloride solution $\left(60 \mathrm{mg}: 6 \mathrm{mg}: 6 \mathrm{mg}\right.$ ) in IPA were poured on $\mathrm{PbI}_{2}$ layer, followed by a spin coating at $1300 \mathrm{rpm}$ for $30 \mathrm{~s}$ and annealed at the $150{ }^{\circ} \mathrm{C}$ for $15 \mathrm{~min}$. Next, the HTM layer was prepared by adding $17.5 \mu \mathrm{l}$ bis (trifluoromethane) sulfonimide lithium salt $(99.95 \%$, Merck) in acetonitrile $(520 \mathrm{mg} / \mathrm{ml})$, and $28.8 \mu 14-$ tertbutylpyridine to $60 \mathrm{mg}$ Spiro-OMeTAD in chlorobenzene. Next, the HTL mixture was fabricated at $3000 \mathrm{rpm}$ for $40 \mathrm{~s}$; it was deposited on top of the PVK film to develop the HTL film. A $70 \mathrm{~nm}$ gold electrode was deposited on the HTM to complete the PSC structure.

\section{Characterization}

The morphological properties of the perovskite layer were observed with a FESEM (TESCAN, Mira 3). X-ray 
diffraction spectra of the perovskites were measured by X-ray diffraction (Bruker, D8 advance). A UV-vis spectroscopy (Analytic Jena, Specord 250) was utilized to determine the optical merits of perovskites. The photoluminescence response of perovskites was characterized using a PL system (Teifsanje, FL-Ar-2015). The photocurrent-voltage $(J-V)$ measurements of the PSCs were evaluated under a calibrated power density of 100 $\mathrm{mW} . \mathrm{cm}^{-2}$ (one sun) using a Keithley Model 2400. The active area of $8 \mathrm{~mm}^{2}$ was used.

\section{Results and Discussion}

SEM images were used to examine the morphologies of the perovskite films, as shown in Figure 1. Compared to pure $\mathrm{mp}-\mathrm{TiO}_{2}$ based perovskite, a suitable PVS film for solar cell applications may be produced by adding $\mathrm{rGO} / \mathrm{Bi}_{2} \mathrm{O}_{3}$. The perovskite's pinholes and grain boundaries (GBs) were enervated. Because they functioned as charge recombination sites, they were inappropriate for PSCs. This modification approach may decrease the density of trap states between the GBs, increasing the suppression of recombination processes and promoting the efficiency of the PSC, which is consistent with the findings of the PL and I-V tests.
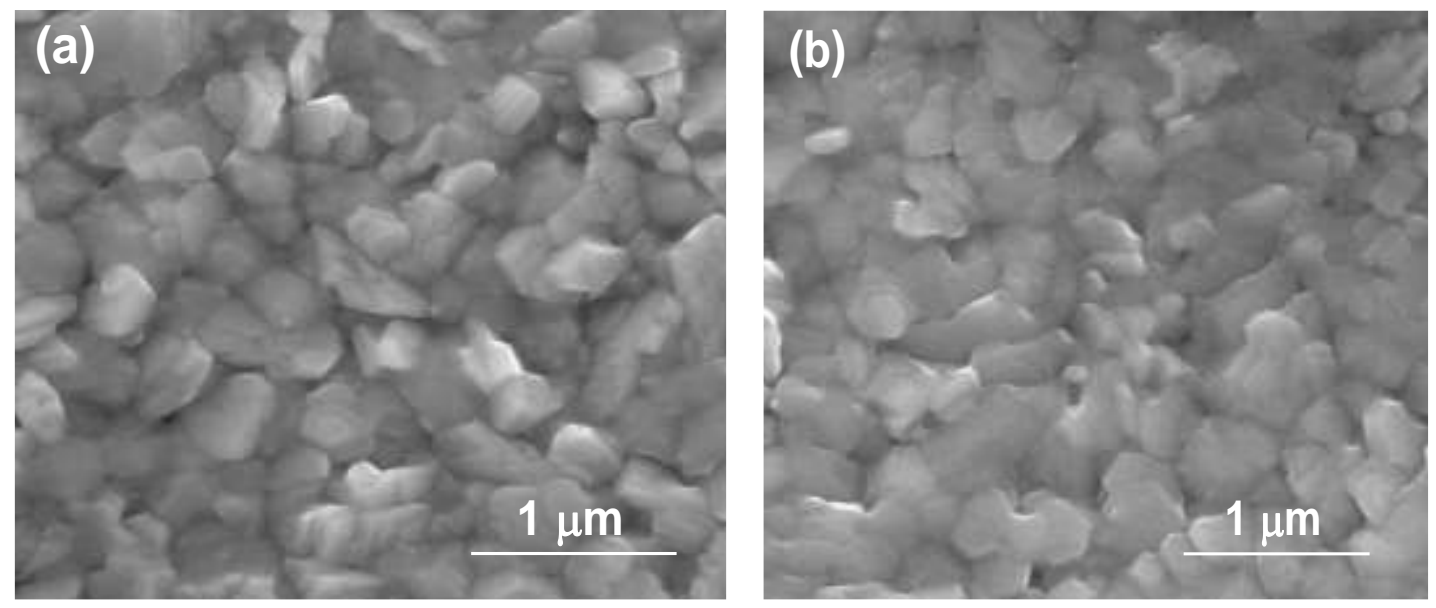

Figure 1: PVS films deposited on mp-TiO ${ }_{2}$ with (a) $0 \% \mathrm{rGO} / \mathrm{Bi} 2 \mathrm{O} 3$ modified mp- $\mathrm{TiO}_{2}$ and (b) $4 \% \mathrm{rGO} / \mathrm{Bi}_{2} \mathrm{O}_{3}$ modified mp- $\mathrm{TiO}_{2}$.

The UV-vis spectra of PVS films deposited on mp- $\mathrm{TiO}_{2}$ ETLs are shown in Figure 2a. The addition of $2 \%$ $\mathrm{rGO} / \mathrm{Bi}_{2} \mathrm{O}_{3}$ would significantly increase the absorbance of the perovskite layer within the visible wavelength. However, as can be seen, the $\mathrm{rGO} / \mathrm{Bi}_{2} \mathrm{O}_{3}$ nanocomposite did not affect the perovskite's absorption edge. Figure 2b also shows the Tauc plots of perovskite films. The figures show that the bandgap energy (Eg) is approximately $1.58 \mathrm{eV}$ in both cases. The steady-state PL measurements of the perovskites revealed a similarity.

(a)

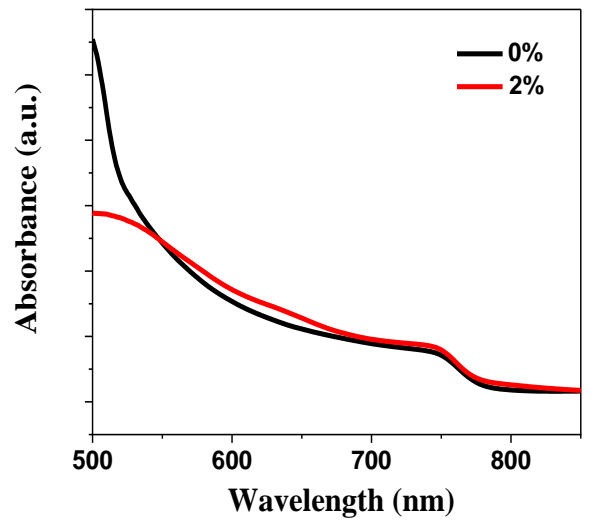

(b)

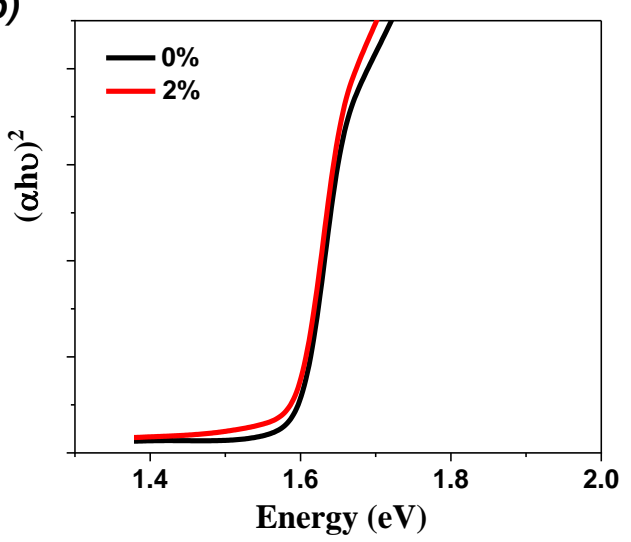

Figure 2: (a)UV-vis absorption spectra, (b) Tauc plots of perovskite films formed on $0 \%$ and $4 \% \mathrm{rGO} / \mathrm{Bi}_{2} \mathrm{O}_{3}$ additives.

The steady-state PL spectra of perovskite films deposited on $\mathrm{rGO} / \mathrm{Bi}_{2} \mathrm{O}_{3}$ additives with different concentrations are illustrated in Figure 3 a. It is clearly seen that the introducing $\mathrm{rGO} / \mathrm{Bi}_{2} \mathrm{O}_{3}$ additive resulted in a quenching of the PL peak, which indicates a more effective carrier's injection in the corresponding perovskites with fewer 
recombination rates. The XRD patterns of perovskites deposited on $\mathrm{mp}-\mathrm{TiO}_{2} \mathrm{ETMs}$ are shown in Figure $\mathbf{3 b}$. In $\mathrm{X}$-ray spectra, the $2 \% \mathrm{rGO} / \mathrm{Bi}_{2} \mathrm{O}_{3}$ additive increased the primary (001) signal, improving the perovskite crystalline nature. $\mathrm{PbI}_{2}$ has a peak at $12.57^{\circ}$, which is overlooked by PSCs. This peak was significantly reduced when $\mathrm{rGO} / \mathrm{Bi}_{2} \mathrm{O}_{3}$ was used, indicating resistance to humid degradation. The tests mentioned above showed that adding $\mathrm{rGO} / \mathrm{Bi}_{2} \mathrm{O}_{3}$ improves ETM characteristics and perovskite quality.

(a)

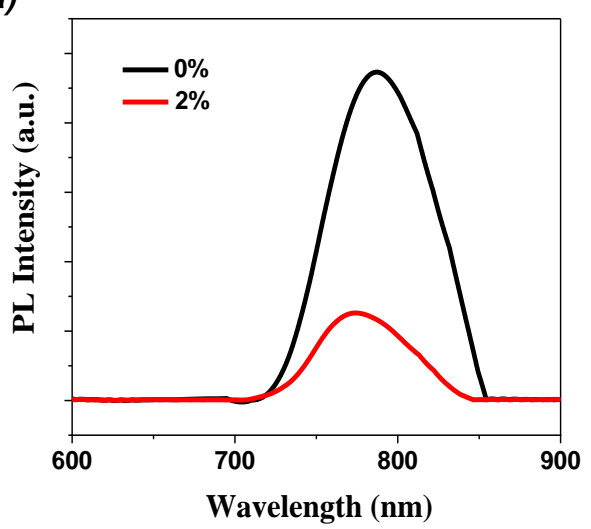

(b)

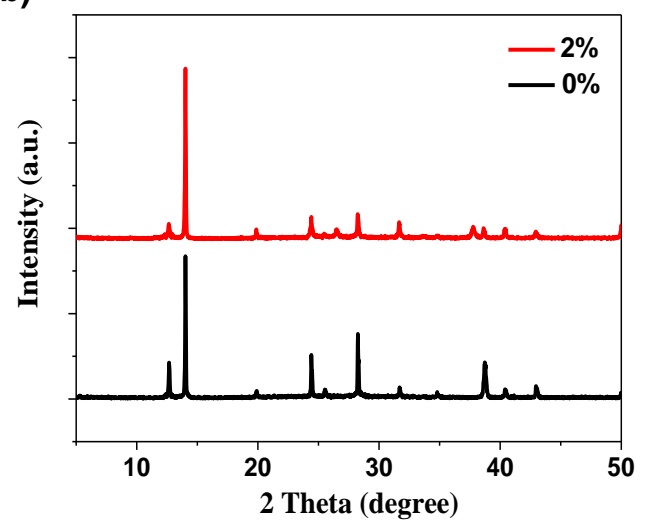

Figure 3: (a) Steady-state PL spectra and (b) XRD patterns of perovskite films deposited on $0 \%$ and $4 \%$ $\mathrm{rGO} / \mathrm{Bi}_{2} \mathrm{O}_{3}$ additives.

Figure 4 shows the $\mathrm{J}-\mathrm{V}$ graphs. In contrast to unmodified cells utilizing a pure ETL, PSCs using $\mathrm{rGO} / \mathrm{Bi}_{2} \mathrm{O}_{3}$ modified ETL showed a $26 \%$ increase in PCE. The PV characteristics of the PSC with $2 \% \mathrm{rGO} / \mathrm{Bi}_{2} \mathrm{O}_{3}$ were Voc of $0.9 \mathrm{~V}$, Jsc of $22.6 \mathrm{~mA} \mathrm{~cm}^{-2}$, FF of $71.7 \%$, and PCE of $17 \%$, whereas the control PSC had Voc of $0.88 \mathrm{~V}$, Jsc of $21.7 \mathrm{~mA} \mathrm{~cm}{ }^{-2}$, FF of $64.1 \%$, and PCE of $13.2 \%$. The electrically conductive properties of $\mathrm{rGO} / \mathrm{Bi}_{2} \mathrm{O}_{3}$ and the low potential of carrier traps, where rGO additives may act as an electron acceptor, could explain this improvement. According to the literature, the improved PSCs' greater Voc is due to their reduced trap density and suppressed recombination processes, which result from better energy level alignment between $\mathrm{TiO}_{2}$ and the perovskite layer.

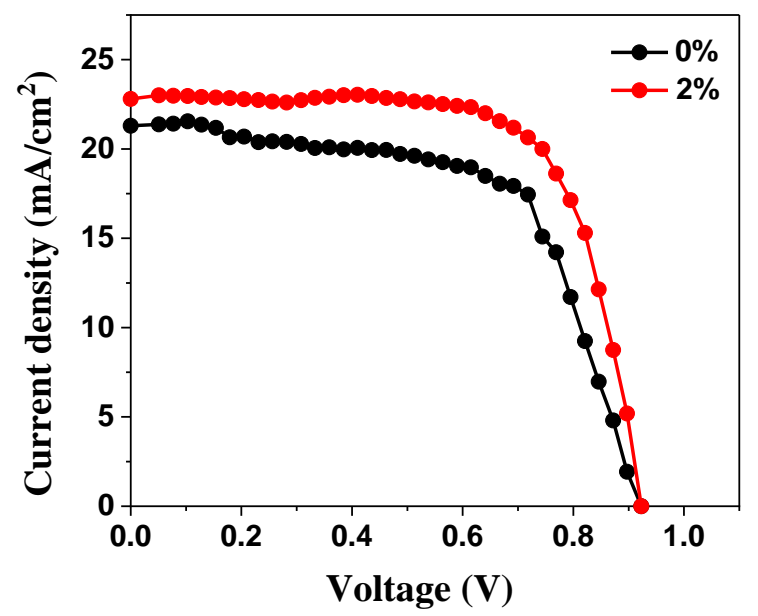

Figure 4: $J-V$ measurements of perovskite solar cells deposited on $0 \%$ and $4 \% \mathrm{rGO} / \mathrm{Bi}_{2} \mathrm{O}_{3}$ additives.

\section{Conclusions}

We provide a new $\mathrm{rGO} / \mathrm{Bi}_{2} \mathrm{O}_{3}$ additive for the fabrication of high-performance mesoporous PSCs. This method uses a nanocomposite structure of $\mathrm{rGO} / \mathrm{Bi}_{2} \mathrm{O}_{3}$ integrated into $\mathrm{mp}-\mathrm{TiO}_{2}$ as an electron acceptor/transport mediator ETLs. $\mathrm{rGO} / \mathrm{Bi}_{2} \mathrm{O}_{3}$-based PSCs have superior charge injection and reduced recombination processes than control 
PSCs, resulting in greater Jsc and PCE. Our findings suggest that $\mathrm{rGO} / \mathrm{Bi}_{2} \mathrm{O}_{3}$ might be a good additive in PSCs to improve the PSCs' PV parameters. Importantly, with the $\mathrm{rGO} / \mathrm{Bi}_{2} \mathrm{O}_{3}$ additive, a champion PCE of $17 \%$ is achieved.

\section{Conflict of Interest}

The authors declare that they have no conflict of interest.

\section{References}

[1] A. Barhoum and A. S. H. Makhlouf, Emerging Applications of Nanoparticles and Architecture Nanostructures. Elsevier, 2018.

[2] A. K. Al-Mousoi and M. K. Mohammed, "Engineered surface properties of MAPI using different antisolvents for hole transport layer-free perovskite solar cell (HTL-free PSC)," Journal of Sol-Gel Science and Technology, vol. 96, no. 3, p. 659-668, 2020.

[3] G. A. Al-Dainy, S. E. Bourdo, V. Saini, B. C. Berry, and A. S. Biris, "Hybrid Perovskite Photovoltaic Devices: Properties, Architecture, and Fabrication Methods," Energy Technology, vol. 5, no. 3, p. 373-401, 2017.

[4] Q. A. Akkerman and L. Manna, "What Defines a Halide Perovskite?," ACS Energy Letters, vol. 5, p. 604610, 2020.

[5] P. Gao, M. Grätzel, and M. K. Nazeeruddin, "Organohalide lead perovskites for photovoltaic applications," Energy \& Environmental Science, vol. 7, p. 2448-2463, 2014.

[6] Y. Y. Choo, "Development and Characterisation of Perovskite Solar Cells," Master, Materials Science and Engineering, Monash University, 2020.

[7] W.-G. Li, H.-S. Rao, B.-X. Chen, X.-D. Wang, and D.-B. Kuang, "A formamidinium-methylammonium lead iodide perovskite single crystal exhibiting exceptional optoelectronic properties and long-term stability," Journal of Materials Chemistry A, vol. 5, p. 19431-19438, 2017.

[8] M. Saliba et al., "Cesium-containing triple cation perovskite solar cells: improved stability, reproducibility and high efficiency," Energy \& environmental science, vol. 9, p. 1989-1997, 2016.

[9] P. Christian, F. Von der Kammer, M. Baalousha, and T. Hofmann, "Nanoparticles: structure, properties, preparation and behaviour in environmental media," Ecotoxicology, vol. 17, p. 326-343, 2008.

[10] F. Alussail, "Synthesis and Characterization of Reduced Graphene Oxide Films," University of Waterloo, 2015.

[11] N. Balis et al., "Investigating the role of reduced graphene oxide as a universal additive in planar perovskite solar cells," Journal of Photochemistry and Photobiology A: Chemistry, vol. 386, p. 112141, 2020.

[12] S. K. Abdulridha, S. A. Tuma, and O. A. Abdulrazzaq, "Study of the Partial Shading Effect on the Performance of Silicon PV Panels String," Journal of Applied Sciences and Nanotechnology, vol. 1, p. 3242, 2021.

[13] J. V. Milić, N. Arora, M. I. Dar, S. M. Zakeeruddin, and M. Grätzel, "Reduced graphene oxide as a stabilizing agent in perovskite solar cells," Advanced Materials Interfaces, vol. 5, p. 1800416, 2018.

[14] M. Batmunkh, C. J. Shearer, M. J. Biggs, and J. G. Shapter, "Nanocarbons for mesoscopic perovskite solar cells," Journal of Materials Chemistry A, vol. 3, p. 9020-9031, 2015.

[15] H.-S. Kim et al., "Reduced graphene oxide improves moisture and thermal stability of perovskite solar cells," Cell Reports Physical Science, vol. 1, p. 100053, 2020.

[16] M. Ghasemi et al., "Phenethylammonium bismuth halides: from single crystals to bulky-organic cation promoted thin-film deposition for potential optoelectronic applications," Journal of Materials Chemistry A, vol. 7, p. 20733-20741, 2019.

[17] C. Lan et al., "Lead-free formamidinium bismuth perovskites (FA) 3Bi2I9 with low bandgap for potential photovoltaic application," Solar Energy, vol. 177, p. 501-507, 2019.

[18] K. Ahmad, "Bismuth Halide Perovskites for Photovoltaic Applications," in Bismuth-Fundamentals and Photonic Applications: IntechOpen, 2020.

[19] O. Üner, N. Aslan, A. Sarığlu, F. Semerci, and M. M. Koc, "Facile Preparation of Commercial Bi2O3 Nanoparticle Decorated Activated Carbon for Pseudocapacitive Supercapacitor Applications," 2021.

[20] N. C. Miller and M. Bernechea, "Research Update: Bismuth based materials for photovoltaics," APL Materials, vol. 6, p. 084503, 2018.

[21] S. Wu et al., "A chemically inert bismuth interlayer enhances long-term stability of inverted perovskite solar cells," Nature communications, vol. 10, p. 1-11, 2019. 
[22] T. Umeyama et al., "Boosting of the performance of perovskite solar cells through systematic introduction of reduced graphene oxide in $\mathrm{TiO}_{2}$ layers," Chemistry Letters, vol. 44, p. 1410-1412, 2015.

[23] N. Hussein and M. M. Khadum, "Evaluation of the Biosynthesized Silver Nanoparticles'’Effects on Biofilm Formation," Journal of Applied Sciences and Nanotechnology, vol. 1, p. 23-31, 2021.

[24] G. S. Han et al., "Reduced graphene oxide/mesoporous $\mathrm{TiO}_{2}$ nanocomposite based perovskite solar cells," ACS applied materials \& interfaces, vol. 7, p. 23521-23526, 2015.

[25] K. T. Cho et al., "Beneficial role of reduced graphene oxide for electron extraction in highly efficient perovskite solar cells," ChemSusChem, vol. 9, p. 3040-3044, 2016.

[26] M. M. Tavakoli, R. Tavakoli, S. Hasanzadeh, and M. H. Mirfasih, "Interface engineering of perovskite solar cell using a reduced-graphene scaffold," The Journal of Physical Chemistry C, vol. 120, p. 19531-19536, 2016.

[27] E. Nouri, M. R. Mohammadi, Z.-X. Xu, V. Dracopoulos, and P. Lianos, "Improvement of the photovoltaic parameters of perovskite solar cells using a reduced-graphene-oxide-modified titania layer and soluble copper phthalocyanine as a hole transporter," Physical chemistry chemical physics, vol. 20, p. 2388-2395, 2018.

[28] H. Mohseni et al., "Enhancement of the photovoltaic performance and the stability of perovskite solar cells via the modification of electron transport layers with reduced graphene oxide/polyaniline composite," Solar Energy, vol. 213, p. 59-66, 2021.

[29] J. V. Patil, S. S. Mali, A. P. Patil, P. S. Patil, and C. K. Hong, "Highly efficient mixed-halide mixed-cation perovskite solar cells based on $\mathrm{rGO}^{-T i O}{ }_{2}$ composite nanofibers," Energy, vol. 189, p. 116396, 2019.

[30] R. Kemat, S. K. Sahari, and A. Baharin, "The Effects of Annealing Temperature Dependence on the Doping of Titanium Dioxide $\left(\mathrm{TiO}_{2}\right)$ and Reduced Graphene Oxide (rGO) for Perovskite Solar Cell Application," International Journal of Nanoelectronics and Materials, vol. 13, 2020.

[31] S. Suragtkhuu et al., "Efficiency and stability enhancement of perovskite solar cells using reduced graphene oxide derived from earth-abundant natural graphite," RSC Advances, vol. 10, p. 9133-9139, 2020.

[32] R. Taheri-Ledari, K. Valadi, and A. Maleki, "High-performance HTL-free perovskite solar cell: An efficient composition of $\mathrm{ZnO} \mathrm{NRs}, \mathrm{RGO}$, and $\mathrm{CuInS}_{2}$ QDs, as electron-transporting layer matrix," Progress in Photovoltaics: Research and Applications, vol. 28, p. 956-970, 2020. 